\title{
Laparoscopic Management of Boerhaave's syndrome: a case report with an intraoperative video
}

\author{
Hager Aref ${ }^{*}$, Tahir Yunus and Obadah Alhallaq
}

\begin{abstract}
Background: Boerhaave's syndrome involves a sudden elevation in the intraluminal pressure of the esophagus, causing a transmural perforation. It is associated with high morbidity and mortality. Its treatment is challenging, and early surgical intervention is the most crucial prognostic element.

Case presentation: We present a case of a 32 year-old male who presented after severe emesis with an acute onset of epigastric pain. He was diagnosed with Boerhaave's syndrome. Displaying signs of shock mandated immediate surgical exploration with laparoscopic primary repair.

Conclusion: The golden period of the first 24 hrs of the event still applies to cases of esophageal perforation. The scarcity of these cases makes a comparison between the various treatment methods difficult. Our data support the use of laparoscopic intervention with primary repair as the mainstay of treatment for the management of esophageal perforation.
\end{abstract}

Keywords: Boerhaave's syndrome, Esophageal rupture, Spontaneous rupture, Laparoscopy

\section{Background}

Boerhaave's syndrome has long been discussed in the medical literature. Dr. Herman Boerhaave described the first case in 1724 [1]. In 1946, Dr. Barrett performed the first successful operation for this rare condition [2].

Boerhaave syndrome or spontaneous rupture of the esophagus is a perforation of the esophagus that results from an abrupt increase in intraesophageal pressure along with negative intrathoracic pressure; for example, after forceful retching or severe vomiting. Esophageal perforation is a rare entity, with an incidence of 3.1 per $1,000,000$ per year [3]. Among all esophageal perforations, about $15 \%$ are spontaneous perforations [4]. Boerhaave syndrome is associated with high morbidity and mortality. It can be fatal if left untreated. Its vague presentation may contribute to a delay in diagnosis and results in poor outcomes [5, 6]. Hence, early surgical intervention is the most important prognostic factor. The standard surgical treatment was through an open

* Correspondence: dr.hageraref@gmail.com

Department of Surgery, International Medical Center, P.O. Box 2172, Jeddah 21451, Saudi Arabia

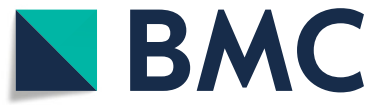

surgical approach, making the case even more challenging to manage in terms of postoperative recovery.

Herein, we present a case of Boerhaave's syndrome, in which laparoscopic repair was successfully performed. In this paper, the authors support the use of laparoscopy for the primary repair of esophageal perforations as the mainstay of treatment. We present this case report to emphasize on the favorable outcome of using laparoscopy in the management of such cases, with an illustration of the intraoperative technique utilized in this case (Additional file 1: Video S1).

\section{Case presentation}

We report the case of a 32 year-old male patient who presented to our Emergency Department with acute onset of unbearable epigastric pain after severe emesis following food ingestion. The pain was radiating to his chest and back and increases by any movement. Due to severe pain and dyspnea, the patient was unable to lay supine insisted on remaining sitting up for the examination. He had an episode of hematemesis after the start of pain. His medical, family, and psychosocial history were irrelevant. He had no previous surgeries performed.

(c) The Author(s). 2019 Open Access This article is distributed under the terms of the Creative Commons Attribution 4.0 International License (http://creativecommons.org/licenses/by/4.0/), which permits unrestricted use, distribution, and reproduction in any medium, provided you give appropriate credit to the original author(s) and the source, provide a link to the Creative Commons license, and indicate if changes were made. The Creative Commons Public Domain Dedication waiver (http://creativecommons.org/publicdomain/zero/1.0/) applies to the data made available in this article, unless otherwise stated. 
Physical examination revealed an anxious patient who looked pale, and dehydrated. His vital signs were, a temperature of $37.5 \mathrm{C}$, heart rate of 103 beats/minute, and the rest were unremarkable. Examination of the cardiopulmonary system was unremarkable. Upon examining the abdomen, the epigastric area was tender with guarding in the upper abdomen but soft at the lower part. No rigidity was appreciated.

His laboratory investigations showed leukocytosis, WBC was $22 \times 109 / \mathrm{L}$. An electrocardiogram was done and showed sinus tachycardia. The chest (Fig. 1) and abdominal x-rays (Fig. 2) showed tiny air collection in the paraspinal space on the left side above the diaphragm, but no free air under the diaphragm and no evidence of pleural effusion.

He was admitted to the Intensive care Unit and underwent $\mathrm{CT}$ of the abdomen and pelvis, which revealed air around the distal esophagus with apparent thickening of the wall of the esophagus, the air was noted at the gastroesophageal junction with air bubbles in the gastrohepatic ligament in the abdomen. A large intramural hematoma is noticed within the gastric fundus and basal infiltration of the left lung. Features were highly suggestive of rupture of the distal esophagus at the gastroesophageal junction with pneumo-mediastinum (Fig. 3).

The diagnosis of Boerhaave's Syndrome was made. Intravenous antibiotic and fluid hydration were initiated.
With signs of peritonitis, hematemesis, and impending shock, he was intubated and taken for laparoscopic abdominal exploration with the possibility of thoracic exploration. As a result, Thoracic surgery team was consulted and involved in the course of management of the case.

Upon entering the abdominal cavity, a generous hematoma was identified in the gastrosplenic ligament and filling the left upper quadrant area. No signs were indicating the presence of an abscess collection, nor a mass. Followed by dissecting through the pars flaccida on the right side of the stomach. The left side dissection initiated by cutting the greater omentum using a smart bipolar (Ligasure) device. The left crus of the diaphragm was identified, and the anatomy of the gastroesophageal.

(GE) junction was elaborated. We identified a $2 \mathrm{~cm}$ longitudinal perforation within the lower third of the esophagus at the posterolateral wall (Fig. 4). We continued the circumferential dissection of the esophagus, preserving the Posterior Vagus nerve. A 38-French gastric calibration tube was carefully advanced across the GE Junction into the stomach. The edges of the esophageal perforation were cleaned, and primary repair was performed with interrupted 2-0 polyglactin (Vicryl) stitches, (Fig. 5). Then, an omental patch was sutured over the perforation area (Additional file 1: Video S1).

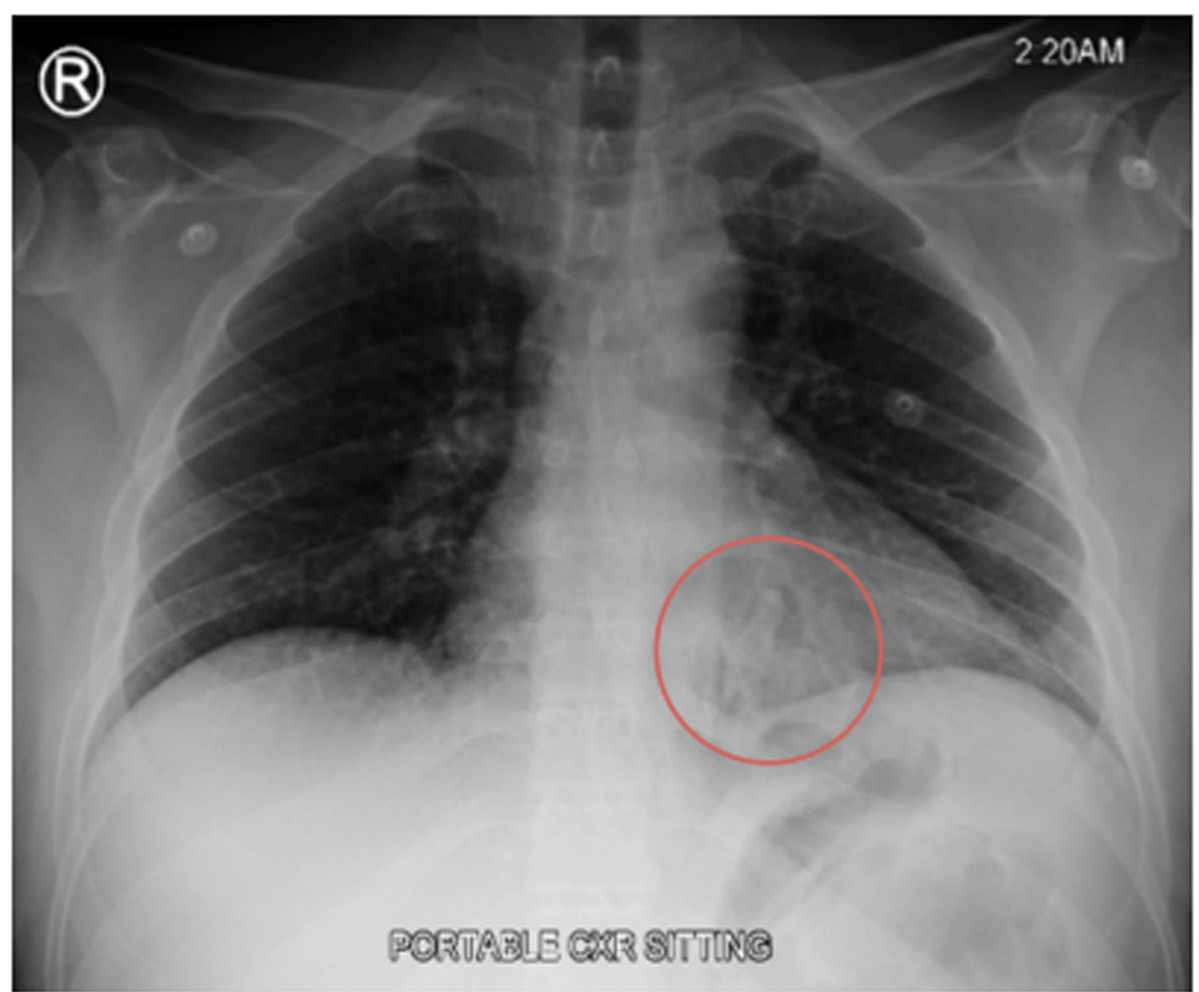

Fig. 1 A Chest Radiograph showed a small air pocket in the paraspinal space 


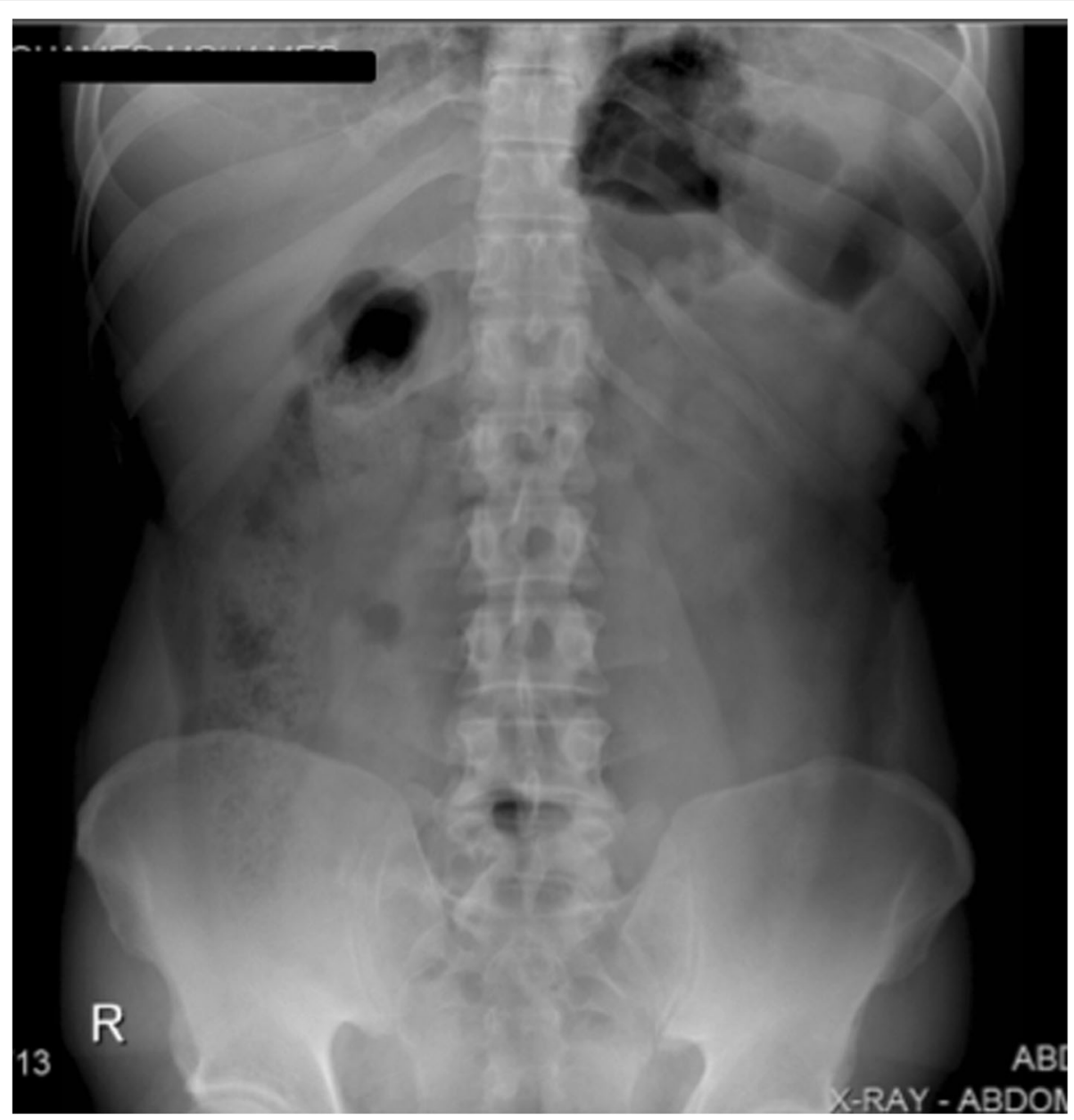

Fig. 2 An abdominal Radiograph showed no intraperitoneal free air, otherwise an unremarkable x-ray

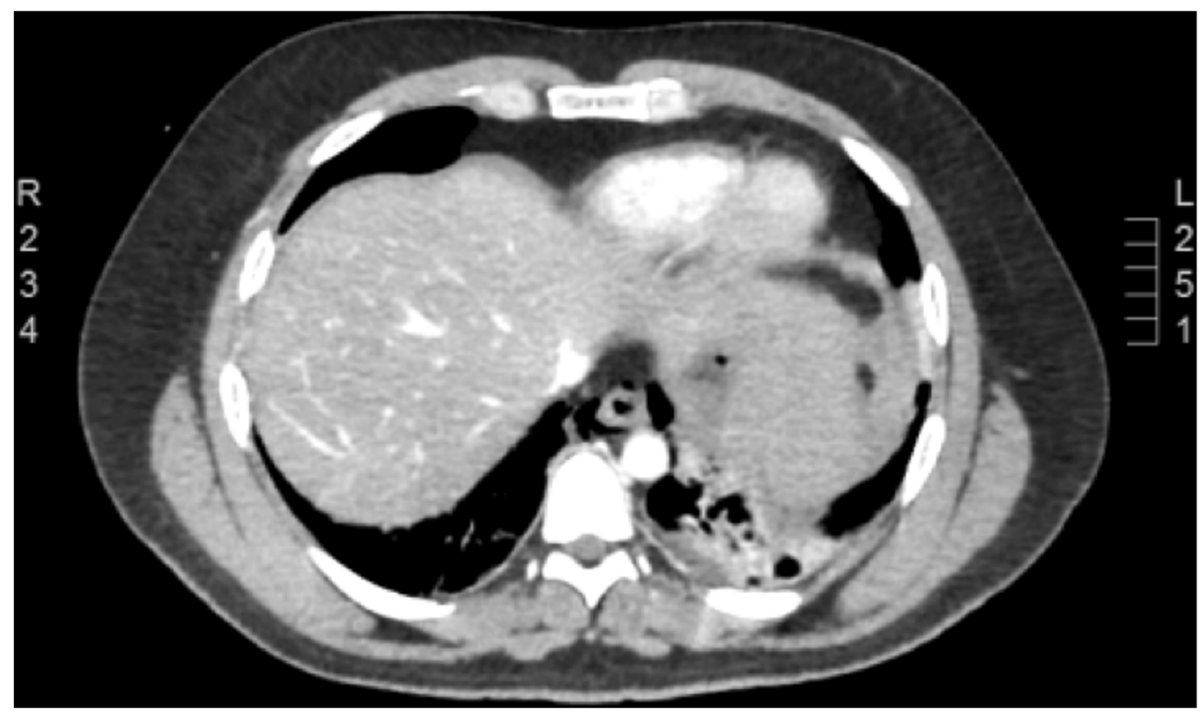

Fig. 3 A CT Abdomen and pelvis, showed esophageal rupture at the gastro-esophageal junction with fundal intramural hematoma 


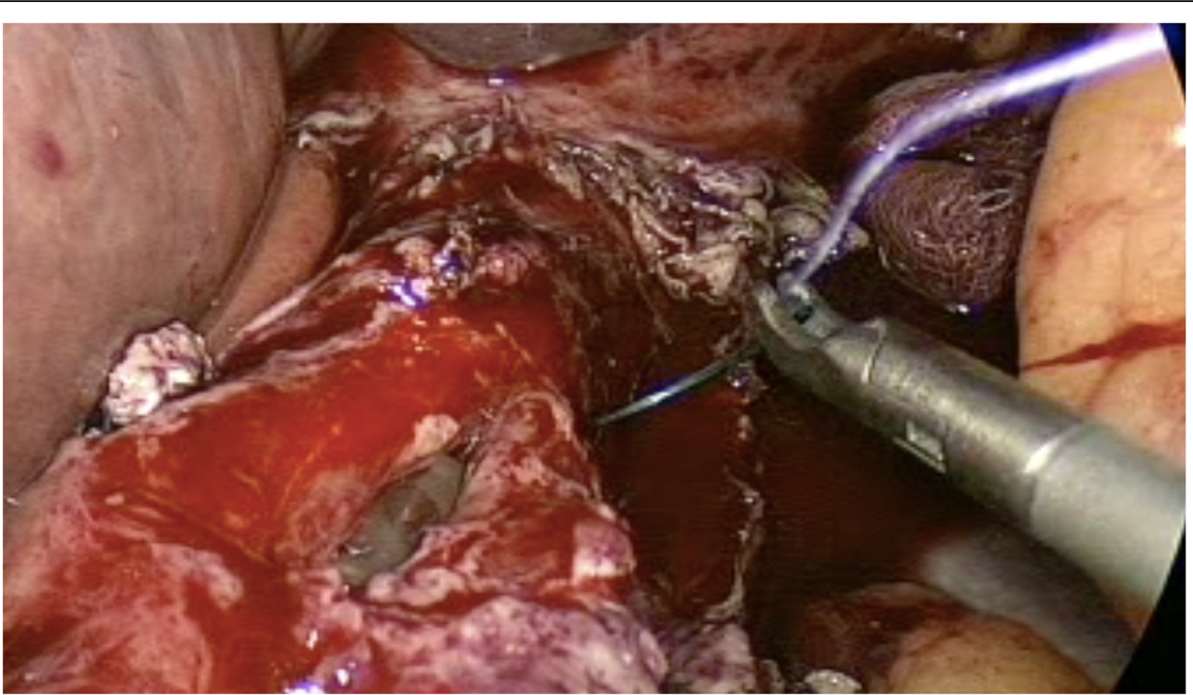

Fig. 4 Intraoperative findings: a perforation in the lower third of the esophagus at the left posterior wall, measuring about $2 \mathrm{~cm}$

A feeding jejunostomy was inserted to gain enteral access for postoperative nutritional support, and a nasogastric tube was advanced into the stomach under intraoperative guidance. Drains were placed intrabdominal and posterior mediastinal.

The patient was then shifted to the Intensive Care Unit. He was kept on the ventilator post-op and extubated the following day. He was kept on antibiotics and was started on jejunostomy feeding.

On postoperative day three, he was transferred to the regular surgical floor. Over a week duration, his leukocytosis resolved. On postoperative day 4, the patient was started on a clear fluid diet, which was well tolerated. One week postoperative, a CT scan of the abdomen-pelvis
(Fig. 6) was performed and confirmed the absence of fluid collections and contrast leak. He was discharged home on postoperative day eight but represented in the emergency room after 2 days with upper back and chest pain that aggravated with respiration. Examination of the chest revealed, left lower chest crepitations. He was afebrile and had a normal leukocyte count. A chest $\mathrm{x}$-ray was done showing pleural effusion, for which he was re-admitted for further management. Upon admission, a repeat CT scan of the abdomen did not show any signs of contrast leakage and confirmed a left basal pulmonary consolidation and minimal left-sided pleural effusion. Pleural tapping with fluid analysis was performed, and he was managed with antibiotics and chest physiotherapy, which facilitated the

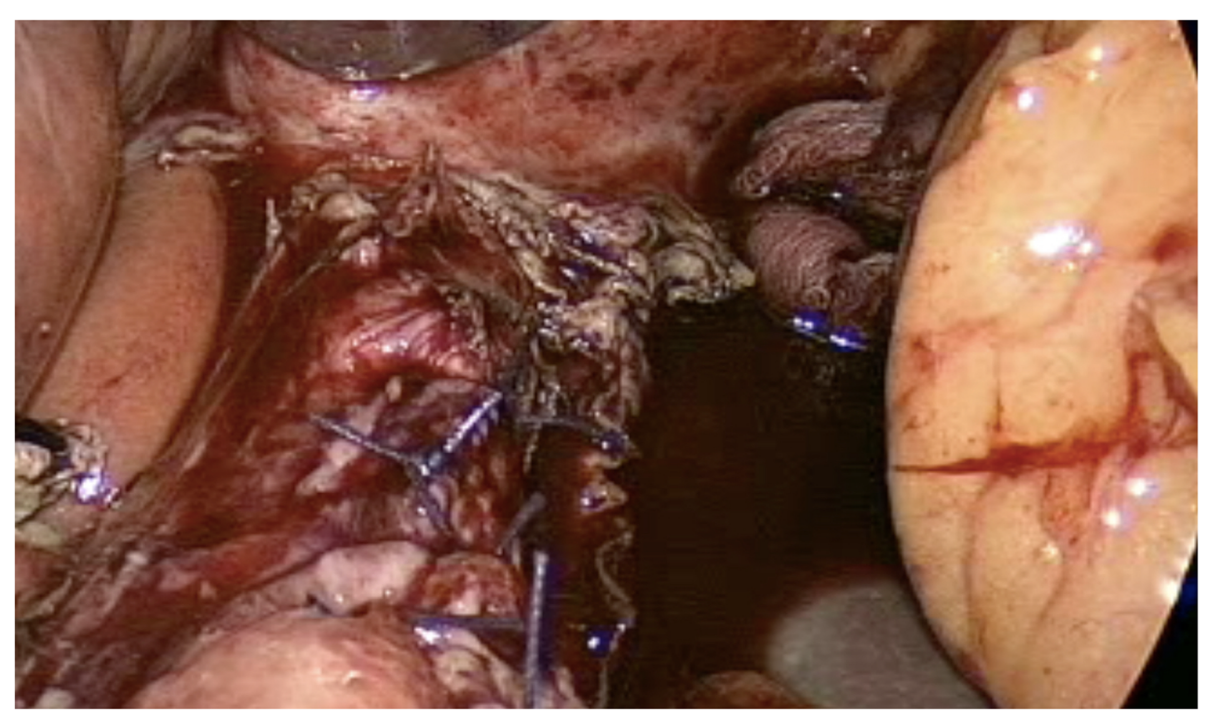

Fig. 5 Intraoperative view following primary repair of the perforation 


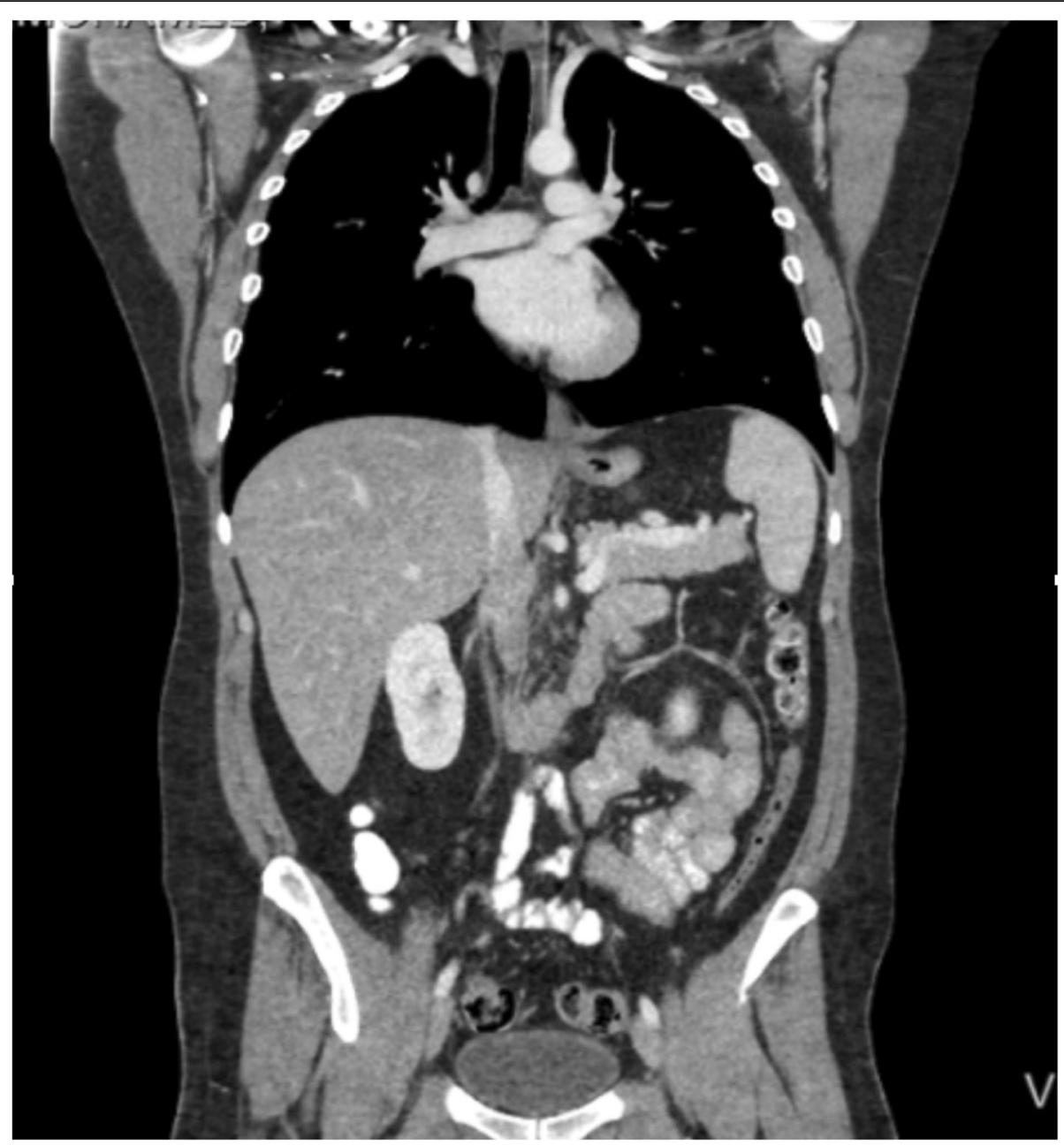

Fig. 6 CT of the chest, abdomen, and pelvis performed in the postoperative setting, showing no evidence of a leak or significant collection

resolution of the pleural effusion. He was discharged home in good condition after a week of hospitalization.

He was reassessed in the surgical clinics and was doing very well with no complains. An upper endoscopy was performed 2 months after the surgery and confirmed normal esophageal and stomach anatomy.

\section{Discussion}

Boerhaave's syndrome refers to spontaneous esophageal transmural rupture [7]. Boerhaave's Syndrome has a mortality rate of $20-40 \%$, which is considered the highest among all etiologies of esophageal perforation $[8,9]$. That goes back to the fact that perforation leads to the leak of acids, enzymatic juices, and micro-organisms, which is causing widespread mediastinal \& pleural contamination [10].

To diagnose this condition, physicians need to have a high index of suspicion. Although, there has been a publication where the classical findings of Boerhaave's syndrome, was described as aiming to help in making the diagnosis. These findings were named as Mackler's triad, and it includes emesis or retching, chest pain, and subcutaneous emphysema. The author has mentioned in his article that, these signs might not all be present in one case [11]. In the case we are presenting, he presented with severe chest pain, difficulty breathing and emesis, but subcutaneous emphysema was not identified. This condition can be confused with other entities such as perforated peptic ulcer, myocardial infarction, and acute pancreatitis, leading to the delay in diagnosis [12]. Hence the high mortality chance of $39 \%$ [13]. All the aforementioned entities were excluded in the presented case by clinical examination, laboratory and imaging investigations.

While having the suspicion of Boerhaave's, radiological studies should be performed to aid confirm the diagnosis and plan surgical intervention. These include plain chest $\mathrm{x}$-ray, which is found to be abnormal in more than $90 \%$ of cases, with free air present in the mediastinal or peritoneal cavity [14]. Less often, with some cases where cervical esophageal perforations are suspected, a person 
may find prevertebral or subcutaneous air on $\mathrm{x}$-ray. Interestingly, those signs were also evident in the described case. Despite the high prevalence of abnormal findings on a chest $\mathrm{x}$-ray, CT scan of the chest and upper abdomen with oral contrast has a better diagnostic advantage and is considered as the preferred diagnostic imaging modality.

The appropriate method for the management of esophageal perforation depends on many factors, such as the severity, time since perforation, the location, age, and status of the patient upon presentation. In such serious condition, surgery is considered as the mainstay treatment, and the outcome depends on early diagnosis, and treatment. The duration between the onset of perforation and surgery should not influence the decision of performing a primary repair.

The literature reported that primary repair of the esophagus complemented by mediastinal and chest drainage is associated with a $90 \%$ success rate. This is especially true in cases where the esophageal rupture is diagnosed early (within $24 \mathrm{~h}$ ) with is no associated esophageal diseases [15-17].

If the diagnosis was late (more than $24 \mathrm{~h}$ ), the outcome was found to be significantly worse, in which operative management is less successful $[18,19]$.

Recent studies have recommended primary repair for esophageal regardless of the time interval between perforations $[20,21]$ and surgery [22].

There have been few reports describing the laparoscopic management of this entity. Studies showed that laparoscopic surgery has many advantages over open surgery, which are a shorter length of stay, faster bowel recovery and earlier mobilization, and less blood loss $[23,24]$.

The trans-hiatal approach results in a shorter length of hospital stay. In a study by Danson et al., the mean length of stay in the laparoscopic approach was 14 days [13]. In contrast, patients who underwent opposed open thoracotomy and washout with primary repair had a longer mean of 20.5 days. In patients who presented the following $48 \mathrm{~h}$ and underwent primary closure over a T-tube, the mean length of stay was longer than the previous group, which is 35.7 days [6]. There were no mortalities in cases managed by laparoscopic trans-hiatal repair, however open thoracotomy and primary repair was associated with a high mortality rate of $20 \%$. These results, strongly support laparoscopic management of this condition. Herein we present an example of successful laparoscopic treatment of a case of Boerhaave's syndrome, which involved primary surgical repair of the perforation. Despite the fact that it was a late presentation; exceeding $48 \mathrm{~h}$ from onset of pain, it had a considerably better outcome as compared to other cases reported in the literature. Furthermore, the total length of stay was significantly less than what was previously reported in the literature of similar cases (total LOS was 8 days for this case, in comparison to 14 days in the literature). This outcome signifies the success of laparoscopic primary repair of esophageal perforation.

\section{Conclusion}

The golden period of the first $24 \mathrm{~h}$ of insult still applies for cases of esophageal perforation. The rarity of these cases makes a comparison between the various methods of treatment difficult. The data presented support the use of laparoscopic operative intervention with primary repair as the mainstay of management of similar esophageal pathology, which showed success even with late presentations. The authors further emphasize the importance of involving a multidisciplinary team in the management of such challenging cases. This includes Intensive care physician, Thoracic surgeon, and laparoscopic surgeon.

\section{Additional file}

Additional file 1: A video showing Intraoperative findings and techniques, (Boerhaave's Syndrome, primary repair of an esophageal perforation). (MP4 355452 kb)

\section{Abbreviations}

CT: Computed Tomography; ER: Emergency Room; GIT: Gastrointestinal Tract; HIS: Health Information System; ICU: Intensive Care Unit; MRI: Magnetic Resonance Imaging

\section{Acknowledgments}

The Authors state no acknowledgment.

This paper was presented as a poster presentation at the 16th World Congress of Endoscopic Surgery, at Seattle, Washington, USA, on 11-14 April 2018 [25].

\section{Authors' contributions}

HA: literature review, finalized the manuscript and submitted the paper for publication. TY: the operating surgeon of the case, he reviewed the manuscript, and wrote part of the discussion and the operating details. OA: editing the discussion and introduction, provided relevant images. All authors have read and approved the final manuscript.

\section{Funding}

No funds were provided before submission.

\section{Availability of data and materials}

All the data presented is contained within the manuscript file.

\section{Ethics approval and consent to participate}

All data reported in the manuscript have been approved for publication by IRB, and all procedures carried out on the patients complied with the Helsinki Declaration. Furthermore, written informed consent was obtained from the patient, and a copy of the consent is available for review by the Editor of the journal upon demand.

Consent for publication

Written informed consent was obtained from the patient for publication of this case report and accompanying images. 


\section{Competing interests}

The authors declare that they have no competing interests.

Received: 22 April 2019 Accepted: 2 August 2019

Published online: 13 August 2019

\section{References}

1. Derbes VJ, Mitchell RE Jr. Hermann Boerhaave's Atrocis, nec descripti prius, morbi historia, the first translation of the classic case report of rupture of the esophagus, with annotations. Bull Med Libr Assoc. 1955; 43(2):217-40.

2. Barrett NR. Spontaneous perforation of the esophagus; review of the literature and report of three new cases. Thorax. 1946;1:48-70.

3. Vidarsdottir H, Blondal S, Alfredsson H, Geirsson A, Gudbjartsson T. Esophageal perforations in Iceland: a whole population study on incidence, aetiology and surgical outcome. Thorac Cardiovasc Surg. 2010;58(8):476-80.

4. Brinster CJ, Singhal S, Lee L, Marshall MB, Kaiser LR, Kucharczuk JC. Evolving options in the management of esophageal perforation. Ann Thorac Surg. 2004;77(4):1475-83.

5. Brauer RB, Liebermann-Meffert D, Stein HJ, Bartels H, Siewert JR. Boerhaave's syndrome: analysis of the literature and report of 18 new cases. Dis Esophagus. 1997;10(1):64-8.

6. Connelly CL, Lamb PJ, Paterson-Brown S. Outcomes following Boerhaave's syndrome. Ann R Coll Surg Engl. 2013;95(8):557-60.

7. Derbes VJ, Mitchell RE Jr. Hermann Boerhaave's Atrocis, nec descripti prius, morbi historia, the first translation of classic case report of rapture of the esophagus with annotations. Bull Med Libr Assoc. 1955; 43(1):217-40.

8. de Schipper JP, Pull ter Gunne AF, Oostvogel HJ, van Laarhoven CJ. Spontaneous rupture of the esophagus: Boerhaave's syndrome in 2008. Literature review and treatment algorithm. Dig Surg. 2009;26(1):1-6.

9. Vial CM, Whyte RI. Boerhaave's syndrome: diagnosis and treatment. Surg Clin North Am. 2005;85(3):515-24 ix.

10. Kollmar O, Lindemann W, Richter S, Steffen I, Pistorius G, Schilling MK. Boerhaave's syndrome: primary repair vs. esophageal resection--case reports and meta-analysis of the literature. J Gastrointest Surg. 2003;7(6):726-34.

11. Griffin SM, Lamb PJ, Shenfine J, Richardson DL, Karat D, Hayes N. Spontaneous rupture of the esophagus. Br J Surg. 2008;95(9):1115-20.

12. Ralph-Edwards AC, Pearson FG. Atypical presentation of spontaneous pneumomediastinum. Ann Thorac Surg. 1994;58(6):1758-60.

13. Jones WG 2nd, Ginsberg RJ. Esophageal perforation: a continuing challenge. Ann Thorac Surg. 1992;53(3):534-43.

14. Ghanem N, Altehoefer C, Springer O, Furtwangler A, Kotter E, Schafer O, Langer M. Radiological findings in Boerhaave's syndrome. Emerg Radiol. 2003;10(1):8-13.

15. Khan AZ, Strauss D, Mason RC. Boerhaave's syndrome: diagnosis and surgical management. Surgeon. 2007;5(1):39-44.

16. Hill AG, Tiu AT, Martin IG. Boerhaave's syndrome: 10 years experience and review of the literature. ANZ J Surg. 2003;73(12):1008-10.

17. Lazar G Jr, Paszt A, Simonka Z, Barsony A, Abraham S, Horvath G. A successful strategy for surgical treatment of Boerhaave's syndrome. Surg Endosc. 2011;25(11):3613-9.

18. Wolfson D, Barkin JS. Treatment of Boerhaave's syndrome. Curr Treat Options Gastroenterol. 2007;10(1):71-7.

19. Sulpice L, Dileon S, Rayar M, Badic B, Boudjema K, Bail JP, Meunier B. Conservative surgical management of Boerhaave's syndrome: experience of two tertiary referral centers. Int J Surg. 2013;11(1):64-7.

20. Jougon J, Mc Bride T, Delcambre F, Minniti A, Velly JF. Primary esophageal repair for Boerhaave's syndrome whatever the free interval between perforation and treatment. Eur J Cardiothorac Surg. 2004;25(4): 475-9.

21. Cho S, Jheon S, Ryu KM, Lee EB. Primary esophageal repair in Boerhaave's syndrome. Dis Esophagus. 2008;21(7):660-3.

22. Turkyilmaz A, Eroglu A, Aydin Y, Kurt A, Bilen Y, Karaoglanoglu N. Boerhaave Sendromu: Ok Kesitili BT bulgulari Turkiye Klinikleri. J Gastroenterohepatol. 2011;2011(18):38-41.

23. Quan Y, Huang A, Ye M, Xu M, Zhuang B, Zhang P, Yu B, Min Z. Comparison of laparoscopic versus open gastrectomy for advanced gastric cancer: an updated meta-analysis. Gastric Cancer. 2016;19(3):939-50.
24. Bedirli A, Salman B, Yuksel O. Laparoscopic versus open surgery for colorectal Cancer: a retrospective analysis of 163 patients in a single institution. Minim Invasive Surg. 2014;2014:530314.

25. Scientific Session of the 16th World Congress of Endoscopic Surgery, Jointly Hosted by Society of American Gastrointestinal and Endoscopic Surgeons (SAGES) \& Canadian Association of General Surgeons (CAGS), Seattle, Washington, USA, 1114 April 2018: Poster Abstracts. Surg Endosc. 2018;32:130-359.

\section{Publisher's Note}

Springer Nature remains neutral with regard to jurisdictional claims in published maps and institutional affiliations.
Ready to submit your research? Choose BMC and benefit from:

- fast, convenient online submission

- thorough peer review by experienced researchers in your field

- rapid publication on acceptance

- support for research data, including large and complex data types

- gold Open Access which fosters wider collaboration and increased citations

- maximum visibility for your research: over $100 \mathrm{M}$ website views per year

At BMC, research is always in progress.

Learn more biomedcentral.com/submissions 